\title{
Performance of the LHD cryogenic system during cooling and excitation tests
}

\author{
T. Mito, R. Mackawa, A. Iwamoto, S. Imagawa, K. Takahata, S. Yamada, N. Yanagi, A. Nishimura, \\ H. Tamura, H. Chikaraishi, S. Hamaguchi, T. Baba, S. Moriuchi, K. Oba, H. Sekiguchi, I, Otake, \\ T. Satow, Y. Nakamura, S. Satoh, O. Motojima, and I.HD Group \\ National Institute for Fusion Science, 322-6 Oroshi-cho, Toki-shi, Gift-ken, 509-5292, Japan
}

\begin{abstract}
Abstrat-Performance of the LIID eryogenic system in the first year's operation was degeribed making importance on the recovery process after the normal transition of the helical coils, During the excitation tests of tle LFD superenducting coils up to $2.75 \mathrm{~T}$, the normal zone propagation was observed in the helieal coil and the emergeney shut-off of the eoil power supplies was carried out. $2,700 \ell$ of liquid helium evaporated from the helieal coils. The coils and the helium refrigerator were scparated antomatically and the helium refrigerator could keep its steady state operation. After the pressure and flow rate of the recovery gas from the helical coils were settled down to the normal state, the coils were connected to the helium refrigerator and the eooling was restarted, The system conld return to the steady stato in whicl coil cxcitation is enabling, by only three and a half lours.
\end{abstract}

Index: Terms-cryogenic system, supereondueting coils, largeseale, LHD, emergency

\section{I. [NIRODUCTION}

The Latge I Ielical Device (LID) is a superconducting, heliotron iype, experimental fusion device, which has the fealure of current-less and steady state plasma confinement. The construction of LHD was completed by the end of 1997 as an eight-year project for the phase i experiment [1]. The LHD cryogenic system succeded in 6400-hours operation in the first ycar, and proved its high reliability [2]. The first cycle operation of I.HD started on February and ended on June in 1998, and the second cycle operation started on $A$ ugust and continued to the end of 1998 . Each cycle consists of a purification, cool down, steady state, and warm-up oporation. It took 670 hours for ist cycle and 569 hours for 2 nd cycte to cool down the total cold mass of 822 tons at $4.4 \mathrm{~K}$ and 34 tons at $80 \mathrm{~K}$.

The plasma experiment was started on March 31, 1998 as planned. 'L'wo experimental campaigns were successfully completed in 1998. The numbers of coil excitations and plasma discharges were 252 and 7132 , respectively. Highperformance plasmas with temperature as high as $2 \mathrm{keV}$ and energy confinement limes as long as 0.23 seconds have been achieved by neutral beam heating. Long pulse operation has also been explored up to 22 seconds for neutral beam heated plasmas and 2 minutes for electron cyclotron heated plasmas.

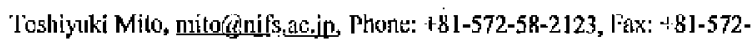
58-1616, 322-6 Oroshi-cho, Toki-shi, Gili-ken, 509-5292, Japan .

\section{FiATURFS OF THIT LHD CRYOGENIC SYSTEM}

The IHD cryogenic system consists of the helium (He) refrigerator, the supercondneting helical and poloidal coils, the supporting stricure, the LHD cryostat, the controlvalve-boxes, the supereonducting bus-lines, the curtent. leads cryostat and the cryogenic transfer-lines as shown in Fig. 1. The helical coils are cooled with pool boiling liquid helium. The poloidal coils are cooled with forced low supercritical hetium (SITe). The supporting structure and the superconducting bus lines are cooled with forced flow twophase helium and the liquid helium is used for the chirtent leads. The $80 \mathrm{k}$ radiation siniclds of the LHD cryostat are cooled with forced flow $40 \mathrm{~K}-80 \mathrm{~K}$ holium gas. The He refrigerator simultatneously has cooling capacities of 5.65 $\mathrm{kW}$ at $4.4 \mathrm{~K}, 20.6 \mathrm{~kW}$ from $40 \mathrm{~K}$ to $80 \mathrm{~K}$ and $650 \mathrm{I} / \mathrm{h}$ liquefaction. The total heat loads undor steady state condition were $1940 \mathrm{~W}+650 \mathrm{~L} / \mathrm{h}(3.0 \mathrm{~T})$ at $4.4 \mathrm{~K}$ and 12.1 $\mathrm{kW}$ at $80 \mathrm{~K}$. The measured hent loads were almost the same as the final design values, which were about half of the cooling capacities.

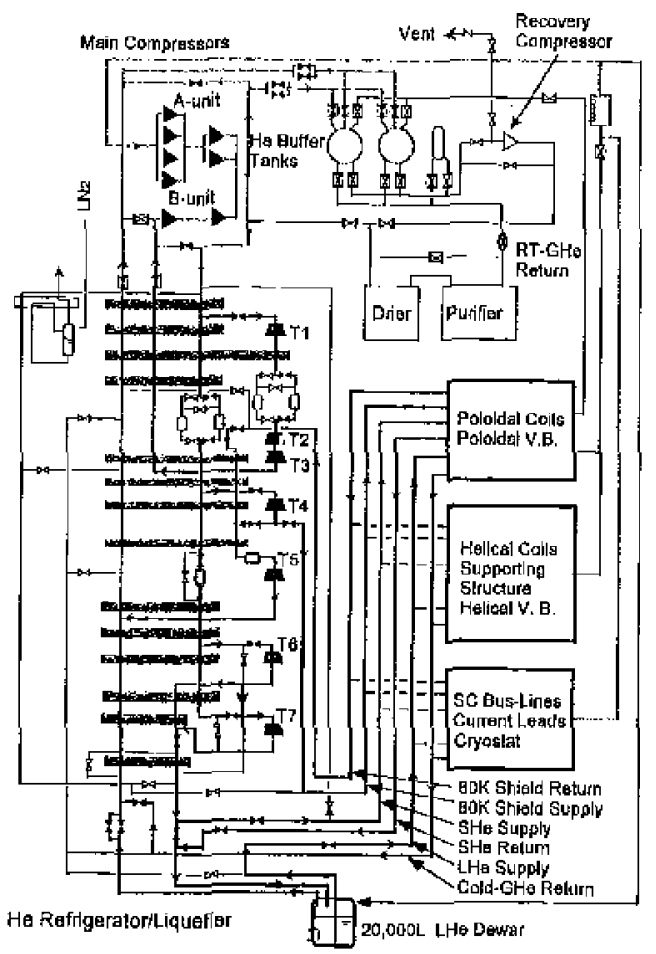

Fijg. 1. Flow diagram of the LHD eryogenic system. 


\section{[1]. EML]RGANCY PROGRAM FOR THE COIL OUINCH}

The emergency scquence programs, corresponding to a power failure, appuratus faults, a coil quench and a successive emergency shut-off of the coil power-supplies and so on, are installed juto the IHHO cryogenic control system (LIID-'TKiSS) [3]. 'The protections of apparatus and recovery in a short time period are possible by the function of them. Whenever any one of superconducting coils or superconducting bus-lines quenches, all coils are disconnected from the power supplies and connected to the dimp resisters. The trabsport currents of the coils are discharged exponentially with a time constant of 20 seconds. These events of a coil qutench and a subsequent emergency current shut-off are abbreviated to 10 . The cryogenic system has to be protected in the case of the quench, which results in evaporation of a lot of liquid hejium and rapid raise of coil pressures due to Joule heating and/or AC losses. The coils are automatically isolated from the He refrigerator with $1 Q$-signal by the emergency sequence program. The coils are protected from the dangerous pressure buildup by the relief valves. On the other hand, the He refrigerator can keep its steady state operation for a quick recovery.

Figure 2 shows changes of a cooling liow for the poloidal coils before and after a coil quench cmergency program (IQ). The doted lines in the figure indicats a cooling flow in the stcady state and the bold solid lines indicates a changed cooling flow after $1 Q$. In the steady state, the upper and lower poloidal coils are connected in scrics and the SHe is supplied from the He reftigerator and toturns to it. After $1 Q$, the poloidal coils are disconnected from the He reftigeratot by closing the coil inlet and return valves. The poloidal coil inlet is directly connected with the discharge of the turbines \# 6 and \# 7 in the He refigerator, and the bypass line is prepared in order to provent the damage of the tirbines by the rapid pressure variation. Therefore, the inlet valve (V1) and the return valve (V2) were closed with 60 seconds ramp speed, while a bypass valve (V3) is opened simultancously. Outlets of upper and lower pofoldal coils (V4, V5) are connected to the buffer tank in order to release and keep the coil pressure same as that of the buffer tank. The liquid hetium (LHe) supply valve (V6) to the SHe heat exchanger $(\mathrm{HXX})$ is also closed in order to disconnect the coil and the $20,000 \&$ LFe Dewar.

Figure 3 shows changes of a cooling flow for the helical coils before and after $1 Q$. In the stcady state, the liquid helium is supplied to the helical coils with pool boiling from tho bottom of the coils. I ow-quality two-phase helium supplied from the LHe Dowar is coolod by a heat exchanger installed in the vapor-liquid-separation reservoir at the helical valve box (H-VB), it turns into the single-ptuase liquid helium, and is supplied to the helical coil and the supporting structure. After 1Q, the helical coils are isolated from the He refrigerator by closing the coil inlet valve (V1, V2) and outlet valve (V3). Once the pressures in the helical coits cxceed the limits, the multi-stage pressure relief valves operate. There are two kinds of program-controlled pressure relief vaives; two recovery valves (the operating pressure of $0.137 \mathrm{MPa}$ ) are connected to the room temperature (RT) recovery line, two release valves $(0.157$ $\mathrm{MPa}$ ) are connected to the vent linc. Ten spring-loaded safely valyes $(0.181 \mathrm{MPa})$ and ten rupture disks $(0.216$ $\mathrm{MPa}$ ), are also set up in the helical coil header. The inlet valves for the supporting structure and shell arms are also closed to isolate then from $20,000 \mathrm{e}$ LHe Dewar. The outlets of the supporting structure and the vapor-liquidseparation reservoir are connected to the RT recovery line.

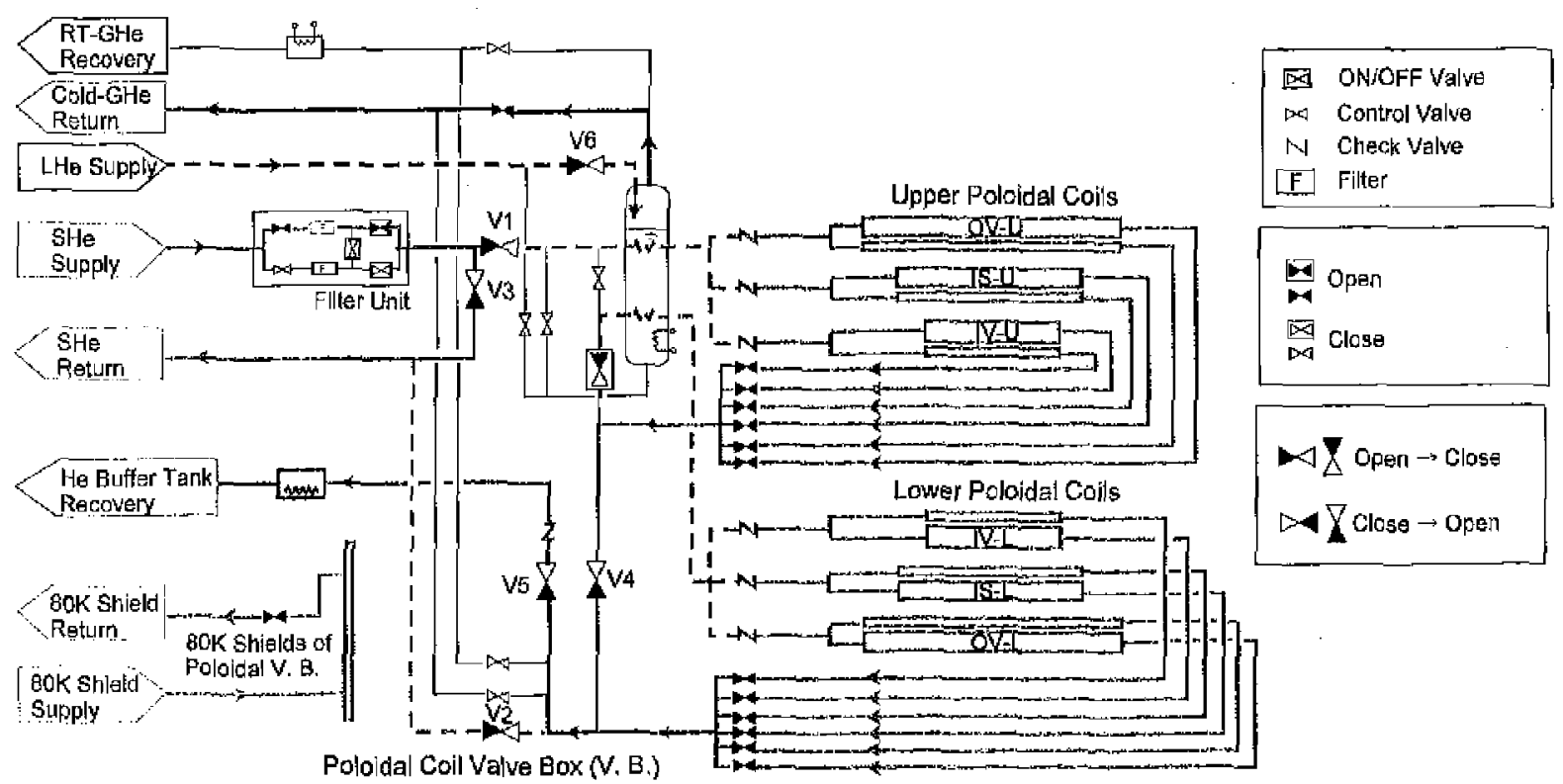

Fig. 2. Changes of a cooling flow lor the poloidal coils after a coil quench emergency program (1Q). 


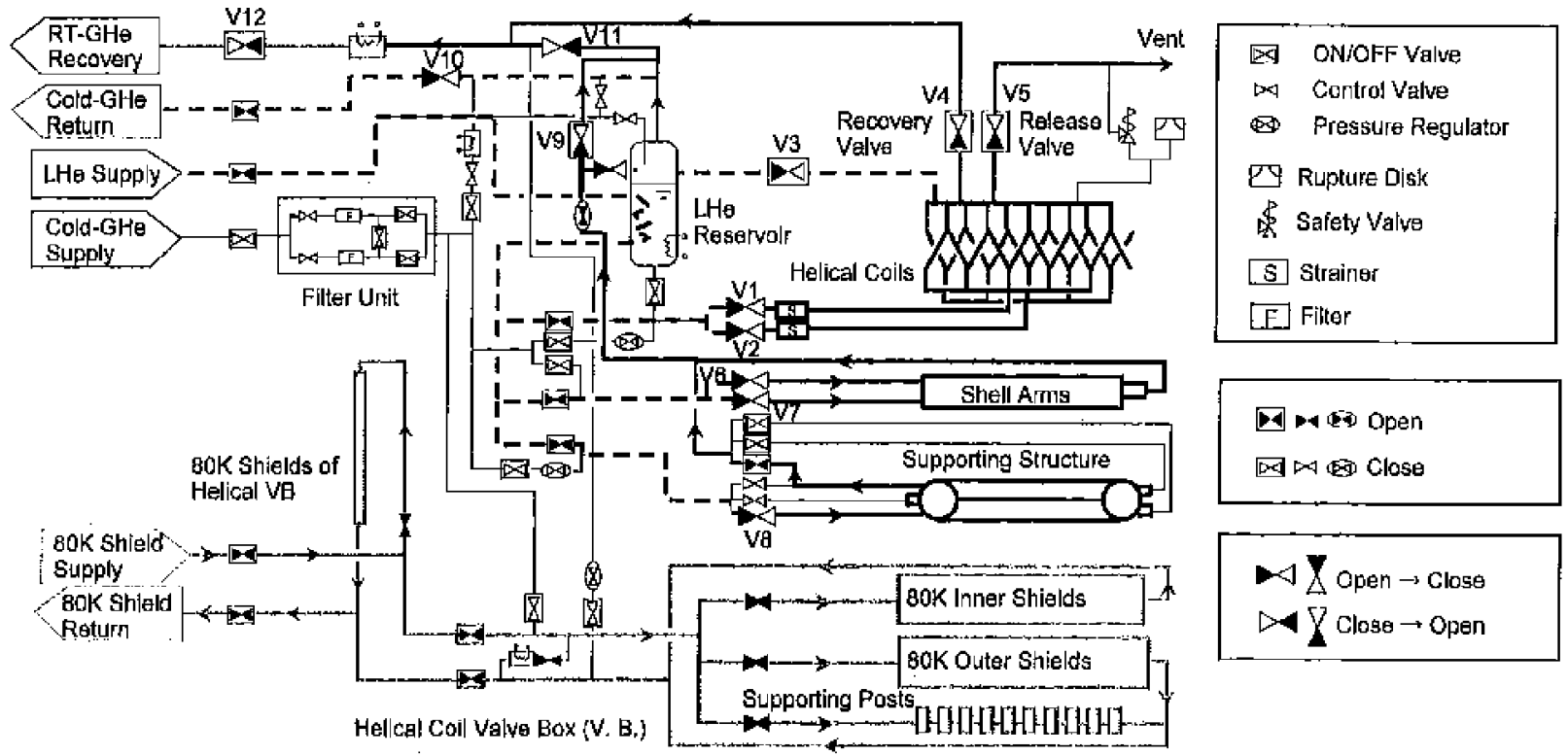

Fig. 3. Changes of a cooling flow for the hetical coils and the supporting structure after $1 \mathrm{Q}$.

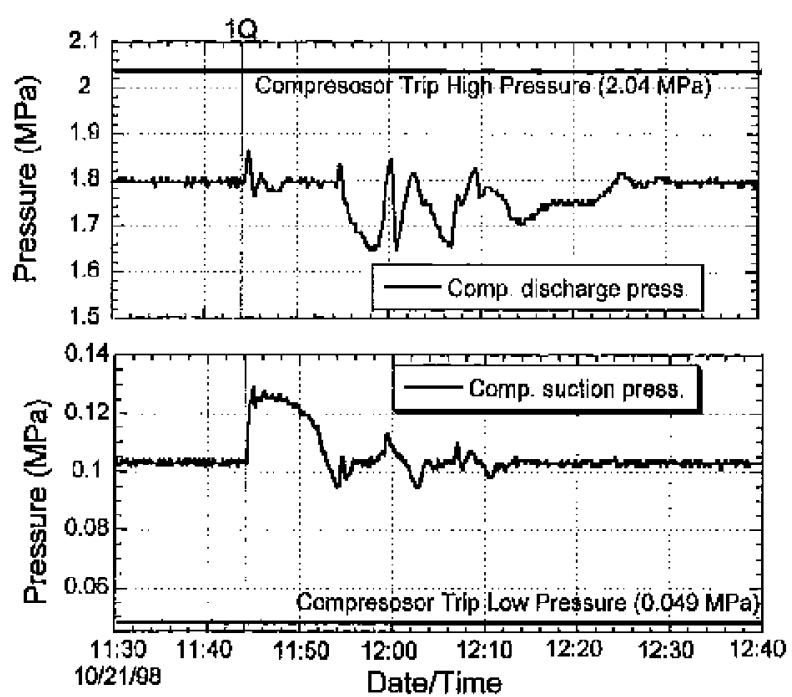

Fig. 4. Fluctuation of the main compressors inlet and outlet pressures

\section{PERTORMANCHS DURING EXCITATION TESTS}

\section{A. Fmergency process due to the coil quench}

During the excitation tests of the LHD SC coils up to 2.75 $T$, nomal zone propagations and a subsequent coil quench were observed in the helical coil and the emergency shutoff of the coil power supplies (1Q) was carried out $[4,5]$. The coils were isolated from the He refrigerator automatically by the $1 Q$ emergency sequence program. Figure 4 shows the fluctuation of the suction and ischarge pressures of the main compressors when IQ occurs. Although the compressor suction and discharge pressures were fluctuated, there was additional coverage in the
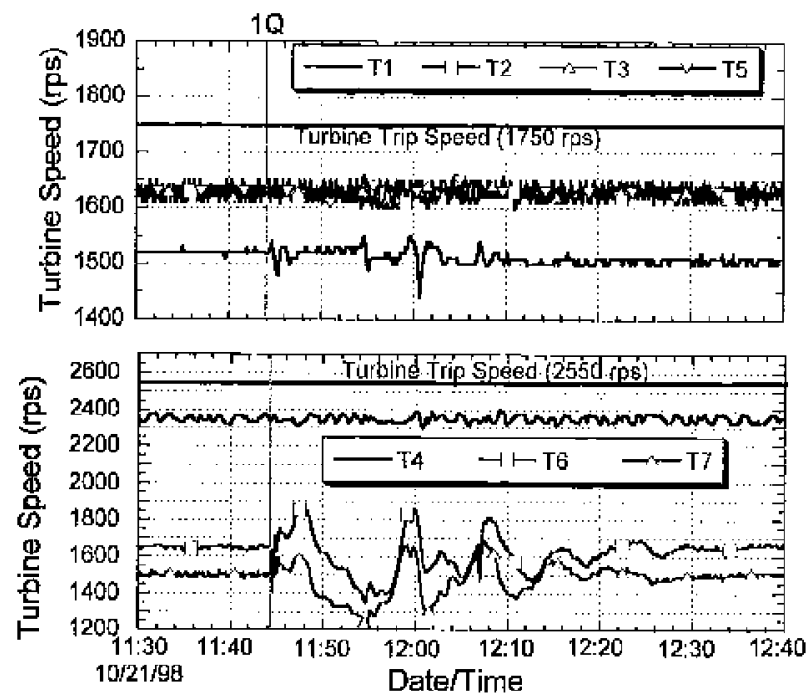

Fig. 5. Fluctuation of the turbine rotational frequencies.

suction-pressure lower limit and the discharge-pressure upper limit in which the compressors carry out a trip. Figure 5 shows the variation of the turbine rotational frequency at the time of IQ. Due to the rapid pressure changes after $1 Q$, the rotational frequencies of turbinus $\$ 6$ and \#7 were fluctuated greatly, however, there was a margin in the upper limit in which the turbines ctrry out a trip. From these data, the Ile refrigerator was ahle to continue the steady state operation after 10 without any trips of turbines and compressors. Figure 6 shows the pressure rise of the helical coil out let header after $1 Q$. Pressure rise of the helical coils was restrained less than $0.177 \mathrm{MPa}$ by the function of the recovery and release valves. The total operating time of the rejease valves, which opened 2 times, was 17 seconds, and the evaporating helium gas of $900 \mathrm{Nm}^{3}$ cxhausted within 1 minute. 


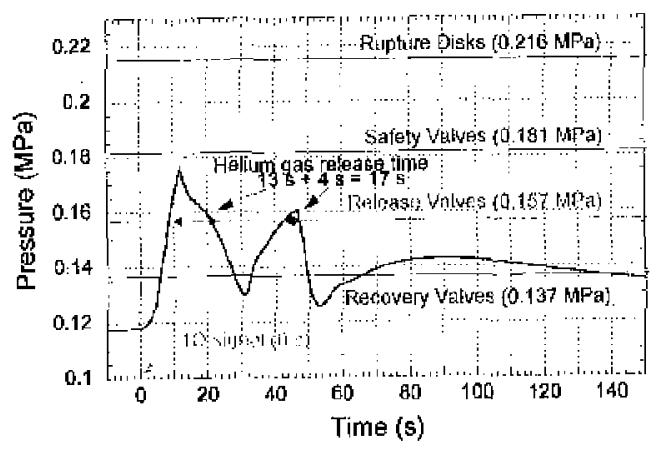

Fig. 6. l'ressure rise of the helical coil header atter $1 \mathrm{Q}$.
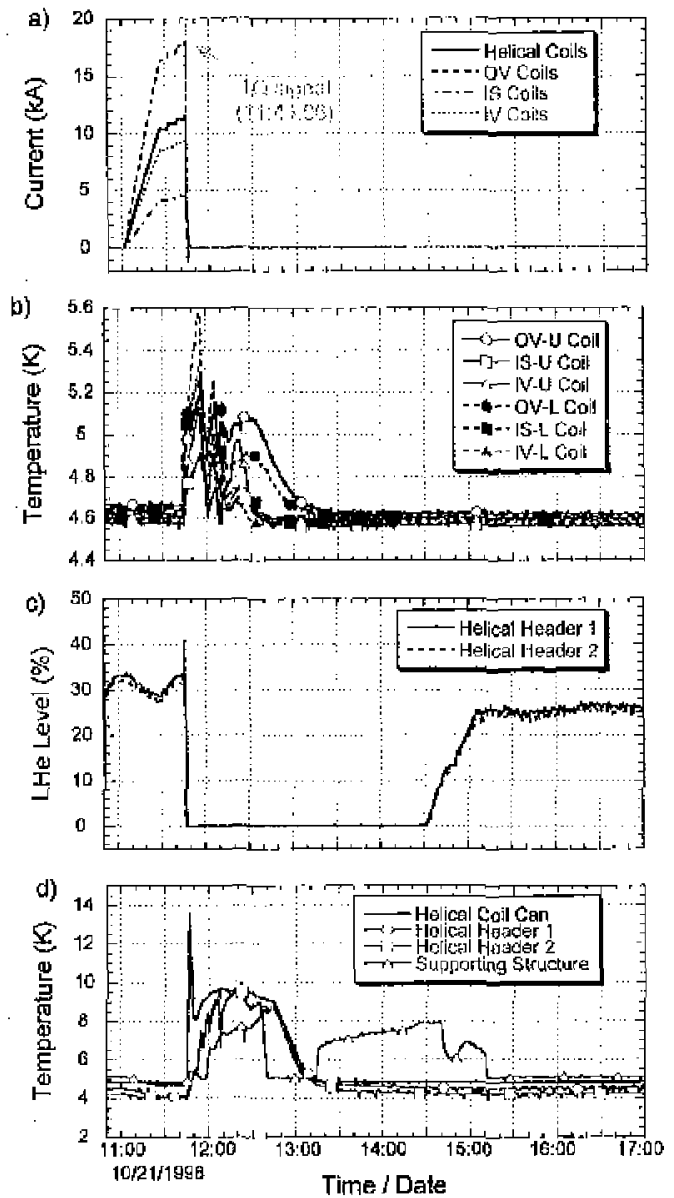

Fig. 7. Rocovery characteristics after $1 Q$, a) Coil currents, b) Poloidal coils outlet temperatures, c) Helical coil header liquid hetium levels, d) Helical coils \& Supporting structure temperatures.

\section{B. Recovery process}

Figure 7 shows the characteristics during the recovery process from 10 ; outlet temperatures of the poloidal coils, liquid helium levels of helical coil header, temperatures of the helical coil cans and the supporting structure. The events fiom the $1 Q$ occurrence to the restoration on October 21, 1998 are listed in Table 1. 2,700 $\ell$ of liquid helium ovaporated from the holical coils. $1,000 \mathrm{Nm}^{3}$ of the evaporated gas was recovered to the helium buffer tanks, while $900 \mathrm{Nm}^{3}$ was exhausted into the air. And, the supplement of the exhausted telium gas and purification were completed at 10:50 of the next day.

Table 1. Events from 19 occurrenec to the restoration

11:44 lo-signal occurrence
He refrigerator and coils were separated

11:55 Helical coils returned to the notmal pressure Evaporated liquid helium was $2,700 \ell$ Recovery gas $1,000 \mathrm{Nm}^{3}$, ex]laust gas $900 \mathrm{Nm}^{3}$

11:56 Poloidal coil SI le cooting restarted

12:25 Supporting structure cooling restarted

12:33 Helical coils LHe supply restarted

13:25 Poloidal coi! outlet temperatures recovered

15:05 ITelical coil header LI le level recovered

15:12 Supporting structure temperatures recovered LHID cryogenic systen restored to the coil-excitation-enable-condition

\section{SUMMARY}

After the normal uransition of the SC coils and the emergency shut-off of the col] power stpplies, it could be restored to the coil-excitation-enable-state only in three and a half hours by the function of the I.HD cryogenic system corresponding to the emergency process. Pressure rise of the helical coils was suppressed less than $0.177 \mathrm{MPa}$ by terms of the recovery and release valves operations, which were progranmed in the I-HD cryogenic control system (LHD-'TESS).

\section{ACKNOWLEDOMMINT}

The anthors are indebted to many siaffs in NIFS who joined and supported LHD as well as many collaborators from universities and national laboratories. The anthors are also grateful to the Nippon Sartso Co, Ltt., the Hiachi Ltd., the Toshiba Co, Fujl Electronic Co., Ltd. for the efforts to construct and maintain LID.

\section{RFEERENCES}

II] I. Mito, et al., "First Cool-Down Perfomance of the LFID," IFFF. Transactions on Appliod Superconductivity! Ptocceding of ASC'9R in Palm Desert, USA, to be published

[2] 'T. Mito, et al., "Reliable Long-tern. Operalion of The Cryogenic Systeth for the Large Ilelical Irevice," Advance in Chogenic Engineering, Procteding of Clic/LCMC: 1909 in Montreal, Canada, 10 be published.

[3] R. Mackawa, at al., "T.JID Ctyogenic-control System Forformance under Various Operating Conditions," Advance in Cryogenic Tisgineering, Proccoding of CFCICMC 1999 in Montreal, Canada, to be published.

[4] S. Imagawa, ot at. "Resu'ts of the First Excitation of I relical Cails of the I arge Felical Device," this conference.

[5] N. Yanagi, et al., "Analysis cn the Normal 'lansition Event of the L[H] ! [elical Coils," this conference. 